Observatório de Inovação do Turismo

\title{
Cruzeiros marítimos: histórico, evolução e tipologia voltados à hospitalidade comercial
}

Cruises ships: history, evolution and typology oriented for hospitality management

\section{Resumo}

No presente artigo, realiza-se uma revisão sistemática dos cruzeiros marítimos, desde a origem até os dias atuais. Fazem-se análises e demonstrações da tipologia dos navios, que se estratificam para uma melhor compreensão de seus diferenciais, e possíveis problemas de comercialização desse serviço turístico no Brasil - principal contribuição deste trabalho para a área de hospitalidade brasileira, pois apresenta a diversidade dos equipamentos existentes no mercado.

Palavras-chave: cruzeiros marítimos, hospitalidade, transporte, passageiros 


\section{Abstract:}

This article provides a systematic review of cruises since its beginning to the present context. Analyzes and demonstrates the types of vessels, as well as stratifies for a better understanding of its differences and possible problems with commercialization of this tourism services in Brazil, which is the main contribution of this paper for the Brazilian hospitality industry, since it presents the diversity of equipment in the market.

Key words: maritime cruises, hospitality, transportation, passenger

\section{Introdução}

Os cruzeiros marítimos compõem um complexo de serviços turísticos que têm como diferencial de mercado o atendimento de grande parte das necessidades e dos desejos dos hóspedes, principalmente pelos diversos benefícios disponibilizados a bordo, como serviço de alimentação 24 horas, estrutura hoteleira completa, transporte, que constituem uma forma de hospitalidade diferenciada que tem agradado muitos turistas brasileiros, mesmo ante a estabilização e a possível saturação de mercado.

Em relação à questão econômica, segundo dados da ANTAQ - Agência Nacional de Transportes Aquaviários (2011) -, 95\% do comércio exterior brasileiro são realizados por via marítima, o que significa, entre exportações e importações, algo em torno de cem bilhões de dólares por ano, sem contar o custo do próprio frete, que gira em torno de seis bilhões de dólares anuais, quase o mesmo valor da receita obtida com toda a exportação de minério de ferro, soja e café.

No intuito de geração de divisas, necessita-se ressaltar a potencialidade dos cruzeiros marítimos como um mercado significativo para essa conta, e, 
principalmente, como fonte de recursos para as localidades litorâneas que deles se beneficiam, principalmente pelo fluxo de turistas que empreendem.

Segundo dados da ABREMAR (2013), na última temporada brasileira de cruzeiros marítimos de cabotagem (2012/2013), em 15 navios, onde se hospedaram 732.163 passageiros, 9,06\% abaixo da temporada anterior (2011/2012), registraram-se 805.189 passageiros, o que representa um grande contingente de viajantes. Na temporada 2013/2014, prevê-se uma oferta15\% menor em número de leitos, pois se dispõe de apenas 12 navios.

A diminuição do fluxo de passageiros deve-se à reformulação dos cruzeiros marítimos nacionais com o aumento de duração das viagens de três a quatro dias para roteiros de sete a oito dias, que oportunizam novos destinos de parada e mais serviços de bordo aos passageiros. A duração maior dos cruzeiros facilita também a operação dos navios nos portos, visto que os processos de embarque e desembarque são extremamente complicados, tanto para os tripulantes na área interna, principalmente em relação à higienização geral, como também pela própria operação de embarque e desembarque que consome tempo e muitos funcionários para a concretização.

Constata-se, pois, a necessidade de outras medidas para atender aos novos desejos e perfis de consumo dos passageiros: variação nos roteiros, vinda de embarcações das mais diversas categorias para servir às variadas gamas de clientes - desde navios de construção clássica até grandes transatlânticos contemporâneos -, tendo-se o adendo, neste último caso, em razão da multiplicidade de atrativos que se conferem a essas embarcações, a função de convir aos destinos turísticos dos passageiros.

Nesse sentido, no presente artigo, analisam-se a evolução, o histórico do segmento e a tipologia das embarcações para que se compreendam as limitações, mas principalmente os diferenciais de mercado ofertados por esse equipamento de hospitalidade. Pretende-se que essa visão ampliada do 
segmento possibilite gerar novas formas de interpretação para que ocorra a retomada de crescimento do setor.

\section{Fundamentação Teórica}

\subsection{A História dos Cruzeiros Marítimos: o Início, o Apogeu e a Maturidade Inovativa}

Neste item, visa-se esclarecer a origem dos cruzeiros marítimos como equipamento de lazer e turismo, desde a origem, como transporte de linha regular utilizado para cargas e pessoas - com o intuito de imigração ou migração -, até os dias atuais, como um prestador de hospitalidade comercial aos hóspedes.

Alguns pesquisadores consideram a Bíblia católica uma das primeiras referências sobre a navegação, mais precisamente o "Livro de Isaías", em que há referência ao povo que habita uma terra onde ocorre o roçar de muitas asas de insetos, que está muito além dos rios da Etiópia e "que envia embaixadores por mar navegando em navios de papiro" (apud COLLINDER, 1954, p.122).

Nessa passagem, lê-se o registro mais remoto de viagem do homem pelo mar, ocorrido, provavelmente, há cinco mil anos, embora, até hoje, haja discordância entre os historiadores sobre a época da edição da Bíblia. Entretanto parece ser um dos primeiros relatos de navegação que se tem conhecimento, em razão do fato de a linguagem escrita ser restrita e pouco difundida em tal período.

Não há dúvidas de que o homem tenha feito muitas viagens pelo mar e por outros territórios antes desse período. A utilização de canoas de pele e demais meios de transporte não devem ser descartadas, conforme Torre: "Desde a antiguidade, o homem ocupou os vales circundantes dos grandes rios, 
como o Tigre, o Eufrates e o Nilo. É possível que, ao ver flutuando algum tronco de árvore, tenha surgido nele a primeira ideia de embarcação" (TORRE, 2002, p. 184).

Buscando-se uma orientação mais precisa, no trabalho em tela, por meio dos grandes momentos históricos do Ocidente, apresenta-se a navegação marítima, no decorrer dos tempos, como uma atividade muito flexível e adaptada à evolução histórico-tecnológica, chegando a ser fonte primordial de renda de muitos países, como o ocorrido no período da expansão marítima europeia. Assim, cabe um adendo sobre a Escola de Sagres, localizada em Portugal, origem da seguinte observação:

Fundada em 1417, a Escola de Sagres funcionou como polo coordenador e executor das futuras expedições marítimas lusas. Esse centro de estudos e pesquisas de navegação reunia astrônomos, geógrafos, matemáticos, especialistas em instrumentos náuticos, além de cartógrafos e navegadores. Foi ao seu tempo o mais avançado centro de estudos náuticos de todo o mundo, catalisando o anseio nacional de criar uma nova rota comercial com o Oriente, conquistando o valioso comércio de especiarias (DEYON, 1973, p. 63).

Muitas técnicas de navegação originaram-se e difundiram-se com essa Escola, e alguns procedimentos são ainda utilizados, como a notação de distância em nós, o guiamento pelos astros (mapa de localização pelas estrelas, direção do sol e da lua, entre outros), a bússola, a luneta, a cartografia, a sinalização marítima, e demais regras, técnicas e processos para deslocamento ${ }^{1}$.

Tais inovações tecnológicas permitiram que, em Portugal e noutros países europeus, se realizassem deslocamentos de grande curso, pois as técnicas e os equipamentos possibilitavam que as embarcações se afastassem mais do litoral, permitindo assim percorrer maiores distâncias, tanto do litoral

\footnotetext{
${ }^{1}$ A tecnologia desenvolvida na Escola de Sagres pode ser encontrada em vários meios de transporte, do modal aéreo ao terrestre, pois a sua grande contribuição foi fornecer o conhecimento para o deslocamento por grandes distâncias com a segurança de retorno ou correção de rota.
} 
(da pequena para a grande cabotagem) quanto em extensão (percurso) com segurança, principalmente para retorno.

Nesse período, o comércio era o principal motivo impulsionador da navegação de longo curso, e realizava-se, até, o transporte de passageiros para o povoamento das colônias conquistadas (Continente Africano, Américas e Ásia) com o intuito de aumentar o fluxo de ganho dos reinos da Europa, principalmente de Portugal, o que gerou até conflitos entre os estados absolutistas. Ilustrando essa situação, tem-se a seguinte nota:

A contestação francesa ao Tratado de Tordesilhas teve no monarca Francisco I o mais veemente representante. Em 1540, chegou a dizer que o Sol brilhava tanto para ele como para os outros e que gostaria de ver o testamento de Adão para saber de que forma este dividira o mundo... Declarou também que só a ocupação criava o direito, que descobrir um país, isto é, vê-lo ou atravessá-lo não constituía um ato de posse e que considerava como domínio estrangeiro unicamente os lugares habitados e defendidos. São essas as bases da colonização moderna (MOUSNIER, 1973, p.163).

Priorizam-se, assim, duas finalidades simultâneas nesse período para as embarcações de longo curso: o transporte de cargas (implantação das colônias de exploração para facilitar o processo de comércio) e o transporte de passageiros (colônias de povoamento para atestar a soberania e a defesa das rotas comerciais).

Na fase conhecida como mercantilismo, impulsionou-se o fomento do transporte marítimo de longo curso na Europa, com o sacrifício das grandes massas para o desenvolvimento dessa atividade, principalmente nos escalões mais baixos. Tais pessoas pertenciam ao conjunto de degredados da sociedade, e eram também responsáveis por povoar as colônias desde a origem desse processo histórico: 
A Coroa portuguesa viabilizou, desse modo, o envio de condenados aos coutos metropolitanos, às longínquas possessões ultramarinas e às temíveis galés. A política de degredo estava em pleno compasso com as teorias mercantilistas vigentes no início do período moderno. As intenções que presidem tal política são claras: transformar o ônus em utilidade implicava expulsar os indesejáveis e atribuir a eles uma função nos locais de degredo (TOMA, 2011, p. 440).

As viagens eram extremamente conturbadas, cheias de perigos e realizadas somente por aventureiros em busca de riqueza e párias da sociedade que eram condenados a essa situação. Entretanto, tratando-se de uma atividade econômica lucrativa para os estados, havia necessidade de criar estruturas e situações que permitissem o desenvolvimento seguro e concreto.

Com essa orientação, havia estímulo para que a indústria naval se desenvolvesse com a criação de embarcações mais resistentes e com maior velocidade. As nações e os mercadores associados investiam maciçamente no segmento para sobreviver e até subjugar oponentes:

Os governos davam ênfase, na proporção de seu interesse pelo comércio exterior, à importância de recursos marítimos adequados para transportar seus produtos industriais a outros países. Voltavam sua atenção, portanto, para o estímulo à navegação com o mesmo zelo demonstrado no fomento da indústria. Os construtores de navios recebiam prêmios governamentais; os produtos necessários à indústria naval, alcatrão, piche, madeiras fortes etc., eram buscados e podiam entrar no país sem pagar taxas; os homens eram obrigados a ingressar na Marinha - na França, os juízes deviam condenar os criminosos às galés, sempre que possível. Na Inglaterra, a indústria da pesca era estimulada por constituir uma escola de treinamento para os homens do mar. Convencia-se o povo a comer mais peixe e, sem dúvida, a máquina de propaganda da época funcionava para convencer a todos de que o peixe continha elementos que não só eram bons para a saúde, como absolutamente necessários para assegurar uma existência prolongada (HUBERMAN,1982, p. 100).

Resultados desse investimento são expressos pelos Clippers ingleses, veleiros rápidos para a época por causa do conjunto dinâmico de velas, o que diminuía as viagens de um a três dias em relação às embarcações concorrentes, 
dominando assim os mares no século XIX. Essa inovação, em razão da agilidade, possibilitou as viagens de passageiros (relação tempo $X$ deslocamento), como o grande fluxo de estudantes das colônias no Novo Mundo para as metrópoles europeias. Na segunda etapa desse desenvolvimento, há o fluxo de imigrantes em embarcações a vapor, muito mais confiáveis e que navegavam com maior velocidade que as embarcações à vela, a partir do século XX.

A história da navegação marítima, como fonte de lazer, tem início com os navios de linha regular. A primeira a executar esse exercício, Deux Frères, foi uma embarcação francesa que, em 17 de dezembro de 1784, segundo Ward (1999, p.10), inaugurou o trajeto circular e contínuo entre Le Havre, na França, e Nova lorque, nos EUA. Um transporte sem o luxo e o conforto dos navios atuais, entretanto com um serviço de bordo próximo ao de um hotel simples, o que, naquele período, significava um avanço no deslocamento de passageiros.

A partir daí, ocorre o desenvolvimento de várias empresas marítimas de linha regular que possibilitaram o deslocamento programado dos viajantes, isto é, as pessoas passam a poder planejar-se conforme a flexibilidade de tempo das companhias marítimas. No entanto isso não significava uma liberdade total para o viajante, pois o roteiro deveria adequar-se às linhas de navegação e ao tempo de espera pela próxima embarcação.

Esse tipo de viagem ainda é possível na atualidade, não obstante a oferta ser escassa e pouco usual em matéria de deslocamento $X$ tempo, por ser mais rápido e até mais barato executar-se por meio de transporte aéreo, além de não existir, nas embarcações específicas, equipamentos e serviços de lazer encontrados nos navios de cruzeiros marítimos - exceto, apenas, nos casos de migração, em razão do volume a ser transportado, que, em proporções de valor por milha $\mathrm{X}$ volume de carga transportado, torna-se uma solução mais econômica. 
Nesse sentido, as companhias marítimas que podem ser ressaltadas como principais naquele momento (e ainda atuantes) são as inglesas $P \& O$ (Peninsula and Oriental Steam Navigation) $)^{2}$ e Cunard Lines ${ }^{3}$, que se originaram, nesse período, das linhas regulares, porém com seus diferenciais ( $P \& O-$ malha extensa de embarcações e portos e Cunard Lines - luxo a bordo) que permitiram a sobrevivência das duas armadoras até o momento atual.

O conceito de cruzeiro marítimo foi criado em concomitância com a evolução das linhas regulares. Eis a referência ao assunto:

In 1835, a curious advertisement appeared in the first issue of the Shetland Journal Under the heading "To Tourists", it proposed an imaginary cruise from Stromness, around Iceland and the Faroe islands, it went on to suggest the pleasures of cruising under the Spanish sun in winter. So it is said that the journal's founder, Arthur Anderson, invented the concept of cruising (WARD, 2003, p.14).

Em 1840, fundou-se a Companhia Cunard Lines que oferecia um serviço de deslocamento rápido, porém investindo também no luxo (por exemplo, salões decorados com lustres em cristal, piano de cauda para entretenimento) e no conforto dos passageiros na linha regular entre Nova lorque (Estados Unidos da América) e Londres (Inglaterra). Uma rápida expansão, tanto em relação à frota, quanto ao domínio completo do rumo a seguir, conquistou esse diferencial comercial (SCHULTZ; SPRINGER, 1999, p. 8).

Ao realizar um adendo à cronologia, visa-se a apresentar um dado referente a uma empresa que surgiu para concorrer diretamente com a Cunard Lines: a White Star que apresentava embarcações com um tamanho

\footnotetext{
${ }^{2} \mathrm{~A} P \& O$ foi a primeira companhia a realizar deslocamentos com datas específicas de partida e retorno, e a conjugar suas embarcações para que os passageiros pudessem realizar a conexão entre os navios, de forma a conhecer o oceano Pacífico partindo dos Estados Unidos da América (WARD, 2003, p. 38).

${ }^{3}$ A Cunard Lines realizava a linha regular da Europa para o Novo Mundo e foi a primeira empresa a propor o conceito de Volta ao Mundo - To All Parts of The World (WARD, 2003, p. 38).
} 
descomunal para a época as quais desenvolviam uma grande velocidade, incrível naquela época, além do luxo a bordo, que somente era encontrado em castelos ingleses (RONÁ, 2002).

A concorrência parecia criar um novo precedente na navegação de alto luxo em razão da construção de embarcações com quarenta mil toneladas $(269,1 \mathrm{~m} \text { de comprimento, } 28 \mathrm{~m} \text { de largura e } 18 \mathrm{~m} \text { de altura })^{4}$; porém, depois do lançamento do primeiro navio, em 1911, denominado The Olimpyc, a companhia White Star lançou ao mar o Titanic que, segundo Torre (2002, p. 200), era "absolutamente insubmergível", mas naufragou na primeira viagem, no dia 16 de abril de 1912, ao chocar-se contra um iceberg.

Os erros de projeto na construção da embarcação e a ausência de equipamentos de segurança para salvaguarda dos passageiros a bordo (principalmente para o grupo de passageiros da segunda e da terceira classes) $^{5}$ levaram a taxas consideráveis de mortalidade naquele acidente, que repercutiram na White Star e culminaram com a falência naquele mesmo ano.

Por causa desse fato, criou-se a ética para a segurança no transporte marítimo, com a primeira convenção de Segurança de Vida ao Mar (1914 — SOLAS - Safety of Life at Sea), supervisionada até os dias atuais pela IMO (International Maritime Organization, órgão vinculado às Nações Unidas), que é cada vez mais aprimorada para garantir a total integridade dos passageiros de cruzeiros marítimos (IMO, 2013).

\footnotetext{
${ }^{4}$ Os navios da Cunard Lines, maior rival da White Star, tinham, na maioria, menos de vinte mil toneladas. Os navios Lusitania e Mauretania eram os de maior capacidade da frota (31 mil toneladas), embora inferiores em relação ao transporte de cargas e pessoas.

${ }^{5}$ Para os passageiros de primeira classe havia cabines amplas e ricamente decoradas, cujos valores eram de $£ 60,00$ a $£ 260,00$, localizando-se nos decks superiores e com livre acesso às áreas externas da embarcação. Os passageiros de segunda classe, por sua vez, eram aqueles que, individualmente, pagaram valores entre $£ 13,00$ a $£ 79,00$, com comodidades de alimentação e benefícios de circulação semelhantes aos da primeira classe, porém com acomodações inferiores, destinadas a duas pessoas (um beliche). Os passageiros de terceira classe pagavam o valor individual de $£ 7,00$ ou de $£ 25,00$ a $£ 40,00$ pelo conjunto familiar, com direito à alimentação e à acomodação em espaços coletivos (SCHULTZ; SPRINGER, 1999, p. 25).
} 
Retornando à cronologia, na companhia $P \& O$, criou-se, em meados de 1844, a possibilidade de realizarem-se as primeiras excursões para jovens aventureiros europeus, pois havia uma malha de navios que cobria parte do Extremo Oriente, o que possibilitava uma espécie de volta ao mundo. Eis um texto referencial:

P\&O entered the leisure cruising business when, in 1844, the noted novelist William Makepeace Thackeray traveled to Malta, Greece, Constantinople, the Holy Land, and Egypt in a series of $P \& O$ ship connections (DICKSON; VLADIMIR, 1997, p. 2) ${ }^{6}$

No período entre a Primeira e a Segunda Guerra, o transporte marítimo de passageiros sofreu um revés em virtude dos embargos à navegação entre os territórios. Nessa época, ocorreram confiscos de embarcações para proteção dos territórios, com as respectivas reconfigurações internas de transporte de passageiros para armamento bélico.

Segundo Roná:

O advento da Segunda Guerra Mundial veio interromper a natural evolução da navegação de passageiros. O Normandie incendiou-se no porto de Nova lorque quando era transformado em navio de transporte de tropas. O Queen Mary recebeu a companhia de seu irmão mais novo, o Queen Elizabeth, quando o conflito já se espalhava pelos oceanos: também foram utilizados para transporte de tropas e, durante os cinco anos seguintes, transportaram mais de um milhão de soldados para as várias frentes de combate (2002, p. 57).

Ao final desse período, ocorreu o embargo na imigração dos europeus para a América do Norte, o que, aliado ao sucateamento dos navios em virtude

\footnotetext{
${ }^{6}$ Tradução livre do autor: A P\&O entrou no negócio de cruzeiros de lazer quando, em 1844, o notável novelista William Makepeace Thackeray viajou para Malta, Grécia, Constantinopla, Terra Santa e Egito em uma série de conexões realizadas pelos navios da $P \& O$.
} 
da guerra, propiciou uma queda drástica no movimento do transporte regular marítimo de passageiros.

Outro fator preponderante para a queda está relacionado com o crescimento do setor de transporte aéreo, que permitia realizar viagens, com certo perigo, mas em tempo cada vez menor do executado por transporte marítimo. Europeus e, principalmente, norte-americanos estavam "ávidos por reconstruir o mundo civilizado", por intermédio dos negócios, e precisavam, portanto, economizar tempo para obter mais ganho, seguindo a filosofia popular de "tempo é dinheiro", conforme preconizava o Plano Marshall (política implantada pelos Estados Unidos da América na Europa pós-guerra com caráter assistencial econômico e impedimento militar para algumas nações do continente europeu).

In 1958, however, Pan American offered the first nonstop transatlantic crossing when its Boeing 707 jet left New York's Idlewild airport in the evening and touched down early the next morning. This seminal event effectively sounded the death knell for the transatlantic steamship business (DICKINSON; VLADIMIR, 1997, p. 22$)^{7}$

O fim dos transportes marítimos de passageiros de linha regular parecia uma realidade cada vez mais iminente, pois a economia europeia encontravase em colapso. Esse fato remete a uma lógica de não comercialização das viagens regulares, contudo ocorre o fenômeno da maturidade inovativa, impulsionada pela curiosidade dos norte-americanos de conhecer os campos destruídos da Europa, criando-se, assim, grandes levas de aventureiros, entre eles muitos artistas. Essa moda motivou o senso popular para o consumo em

\footnotetext{
7 Tradução livre do autor: Em 1958, entretanto, a Pan American ofereceu o primeiro voo transatlântico sem escalas quando seu jato Boeing 707 deixou o aeroporto Idlewild de Nova lorque numa tarde e pousou na manhã seguinte. Essa iniciativa efetivamente anunciou a morte declarada do negócio de transatlânticos.
} 
troca do sonho americano de se igualar a estrelas de cinema e rádio, fato esse contextualizado por Edgar Morin:

Um Olimpo de vedetes domina a cultura de massa, mas se comunica pela cultura de massa, com a humanidade corrente. Os olimpianos, por meio de sua dupla natureza, divina e humana, efetuam a circulação permanente entre o mundo da projeção e da identificação. Concentra-se nessa dupla natureza um complexo virulento de projeção-identificação. Eles realizam as fantasias que os mortais não podem realizar, mas chamam os mortais para realizar o imaginário $(1967$, p.113).

As embarcações transformaram-se, assim, numa espécie de vitrine, onde turistas de médio poder aquisitivo dividiam espaço com seus ídolos, isto é, no período da Segunda Guerra Mundial, a principal forma de lazer disponibilizada à classe média americana era o cinema, principalmente por causa dos galãs e das divas. Ao perceber essa situação, os armadores, buscando uma forma de salvar as embarcações após a guerra, uniram as "estrelas" aos navios, oferecendo roteiros em que era possível desfrutar de uma viagem de lazer e ainda encontrar artistas a bordo. ${ }^{8}$

A nova funcionalidade das embarcações, conhecida por maturidade inovativa, permitiu uma moderna forma de exploração do segmento que ansiava por viagens de extremo luxo, conforto e lazer. Assim, tornou-se necessária apenas a reestruturação das embarcações para uma nova realidade. A implantação de equipamentos, como bares, restaurantes requintados, áreas de lazer e uma infinidade de outras formas de entretenimento, foi a solução encontrada.

Por meio de investimentos maciços em serviços e ritos de hospitalidade, permitiu-se a sobrevivência das embarcações como equipamento de lazer, pois,

\footnotetext{
${ }^{8}$ Essa estratégia ainda faz muito sucesso no segmento de cruzeiros marítimos, basta lembrar as saídas especiais de algumas companhias que utilizam artistas como atrativo, como o cruzeiro com o cantor Roberto Carlos, que se encontra na décima edição, em 2014, e os temáticos Energia na Veia [Véia], com artistas dos anos 1970, 1980 e 1990.
} 
além dos serviços tradicionais de acolhimento, ocorreu o fenômeno da cortesia e da cordialidade para com o hóspede, fato ainda presente no contexto atual:

[...] a hospitalidade sempre foi atributo de pessoas e de espaços, não de empresas; a observação deve, pois, dirigir-se para o que acontece além da troca combinada, além do valor monetizável de um serviço prestado, para o que as pessoas e os espaços proporcionam além do contrato estabelecido (CAMARGO, 2004, p. 45).

Surgiram, nessa época, empresas que se encontram ainda atuantes e líderes nesse segmento, como Carnival Cruise Line, Holland America Cruise Line, Seabourn Cruise Line, Norwegian Cruise Line.

As empresas consideradas tradicionais no mercado atual de cruzeiro marítimo, como Italian Line, atual Costa Crociere, Hebridean Cruise Line, Cunard Lines, Royal Olimpyc (empresa formada da junção entre Epirotic e Sun Line) e $P \& O$ (atual Princess Cruises, ou, como é mais conhecida nos EUA e no Brasil, o Barco do Amor) são representantes dos primórdios da navegação de lazer. Essas empresas conseguiram modernizar-se e, assim, adequar-se às necessidades e exigências do mercado, sem perder a tradição e a categoria de excelência, que as distingue da maior parte das demais, pois viajar em um cruzeiro da Cunard Lines, especialmente no navio Queen Mary 2, representa uma viagem no tempo, não somente pelo estilo clássico de decoração, mas em virtude de reviver-se um passado de muito luxo, conforto e tradição de uma embarcação de Sua Majestade a rainha da Inglaterra. ${ }^{9}$

Vale ressaltar que, nas empresas Carnival, Seabourn e Hebridean, pertencentes à categoria super premium, a viagem torna-se um momento único, em que ocorre o fenômeno da hospitalidade comercial em sua plenitude, visto ser possível retomar, por exemplo, uma refeição mais cerimoniosa, com a

\footnotetext{
${ }^{9}$ Os navios da Cunard Lines têm a outorga real, estando à disposição do Império Britânico para qualquer situação, até mesmo para remanejo como equipamento bélico se a rainha Elizabeth II necessitar (WARD, 2003, p. 39).
} 
possibilidade de degustar-se não somente os alimentos belamente decorados, mas também de desfrutar-se do momento e do ritual envolvidos.

Outro bom exemplo do serviço exclusivo de hospitalidade a bordo nessas embarcações é a relação cordial entre os passageiros e entre eles e a tripulação, que gera um ambiente cerimonioso, resgatando-se ritos, como acomodar a dama à mesa, trocar gentileza entre cavalheiros, regras de etiqueta que já se perderam ou nem são do conhecimento de grande parte da população.

Deve-se compreender que a manutenção dos ritos de etiqueta e de cordialidade nos navios não é apenas uma mera formalidade de bordo, mas sim uma questão de equilibrar-se a postura pessoal com os padrões de relacionamento social em relação às infraestruturas física e humana de atendimento fornecidas pela embarcação. ${ }^{10} \mathrm{O}$ consumidor espera postura e qualidade do equipamento e dos convivas durante a viagem.

O conceito de hospitalidade comercial surge, assim, como estratégia diferencial nos cruzeiros marítimos em relação aos demais equipamentos turísticos existentes à época, e é grande motivo ainda para expansão no contexto atual, pois, nos navios, apesar da retribuição por parte do hóspede ser institucionalizada em alguns países (taxa de serviço $X$ gorjeta), em grande parte dos destinos o serviço é ofertado acima do status quo tradicional, e é até mesmo uma cultura de vida a bordo:

Se a pessoa acolhe por dever, será que está sendo hospitaleira ou está simplesmente fazendo o que deve? Acredito que ela esteja sendo hospitaleira desde que aquilo que chamei de espírito de hospitalidade seja generoso [...] se um hospedeiro comercial atende bem a seus hóspedes com um interesse autêntico por sua felicidade, cobrando um preço razoável não extorsivo por

\footnotetext{
${ }^{10} \mathrm{Na}$ categoria premium de navios, o Queen Mary 2 destaca-se, pois executa quatro viagens de volta ao mundo durante o ano, e o valor mais econômico é de US\$26.995,00 por pessoa - até o da Cabine Duplex Balmoral cujo valor por pessoa é de US\$516.000,00. A maioria das cabines exclusivas é reservada com um ano de antecedência. Disponível em: http://www.cunard.com/cruise-types/world-cruises/>. Acesso em: 15 dez. 2013.
} 
aquilo que oferece, suas atividades poderão ser chamadas de hospitaleiras [...] Esse tipo de hospedeiro presta um serviço generoso, não mínimo, porque deseja agradar os hóspedes; os hóspedes pagam, não em hospitalidade, mas através de uma soma de dinheiro considerada equivalente a um bom negócio e base para relações amigáveis entre o hospedeiro e o hóspede. Dizer que não se pode considerar que um hospedeiro comercial se comporta com hospitalidade só pelo fato de ele ser pago por seu trabalho é o mesmo que dizer que não se pode considerar que um médico se comporta com compaixão porque ele é pago pelo serviço que presta (TELFER, 2004, p. 59).

Nessa relação é que surge o conceito de custo/benefício dos cruzeiros marítimos, em que a gama de serviços e a forma como são prestados geram maiores atributos aos passageiros que são recebidos a bordo dos navios de lazer conforme o valor pago pela viagem.

Voltando-se ao aspecto histórico, as embarcações de passageiros a lazer começam a navegar pelo litoral brasileiro, mesmo com a existência do Decreto presidencial n.o 123, de 11 de novembro de $1892^{11}$, que não permitia o desenvolvimento da navegação de cabotagem no País. Essa norma deixou de existir, principalmente, em razão de os transportes marítimos serem objetos de segurança nacional, o que acarretou, segundo Prado, a seguinte situação:

Em 1964, a única modalidade de transporte em reconhecida expansão era a rodoviária. A frota marítima defasava-se cada vez mais da tecnologia moderna e reduzia sua participação na disputa de cargas com armadores estrangeiros. Os portos, em sua maioria mal equipados, com pobre manutenção e elevadas tarifas, tampouco atendiam adequadamente à demanda, encarecendo os produtos importados e exportados (PRADO,1997, p. 34).

Com esse panorama, percebe-se que, pela opção adotada no período de Juscelino Kubistchek e sustentada pelos governos posteriores, renegaram-se e negligenciaram-se os demais meios de transporte no Brasil - ferroviários ou

${ }^{11}$ O Decreto $\mathrm{n} .{ }^{\circ 123}$ foi substituído pela Lei de navegação de cabotagem $\mathrm{n}$. 9.432 de 8 de janeiro de 1997. 
hidroviários (usados em vias internas ou fluviais). Segundo Prado (1997, p. 37), os caminhos fluviais ocupam cinquenta mil quilômetros, em que $27.400 \mathrm{~km}$ são navegáveis durante $90 \%$ do ano. Ressalte-se que, especialmente, as vias marítimas, com a presença de um litoral de quase oito mil quilômetros de extensão, possibilitam a tão desejada integração nacional. Como consequência maior, prejudicaram-se as cidades litorâneas que foram renegadas e desvirtuadas da funcionalidade tradicional e do tino natural para escoamento da produção nacional em razão de decisões políticas.

Figura 1. Mapa de linhas de cabotagem

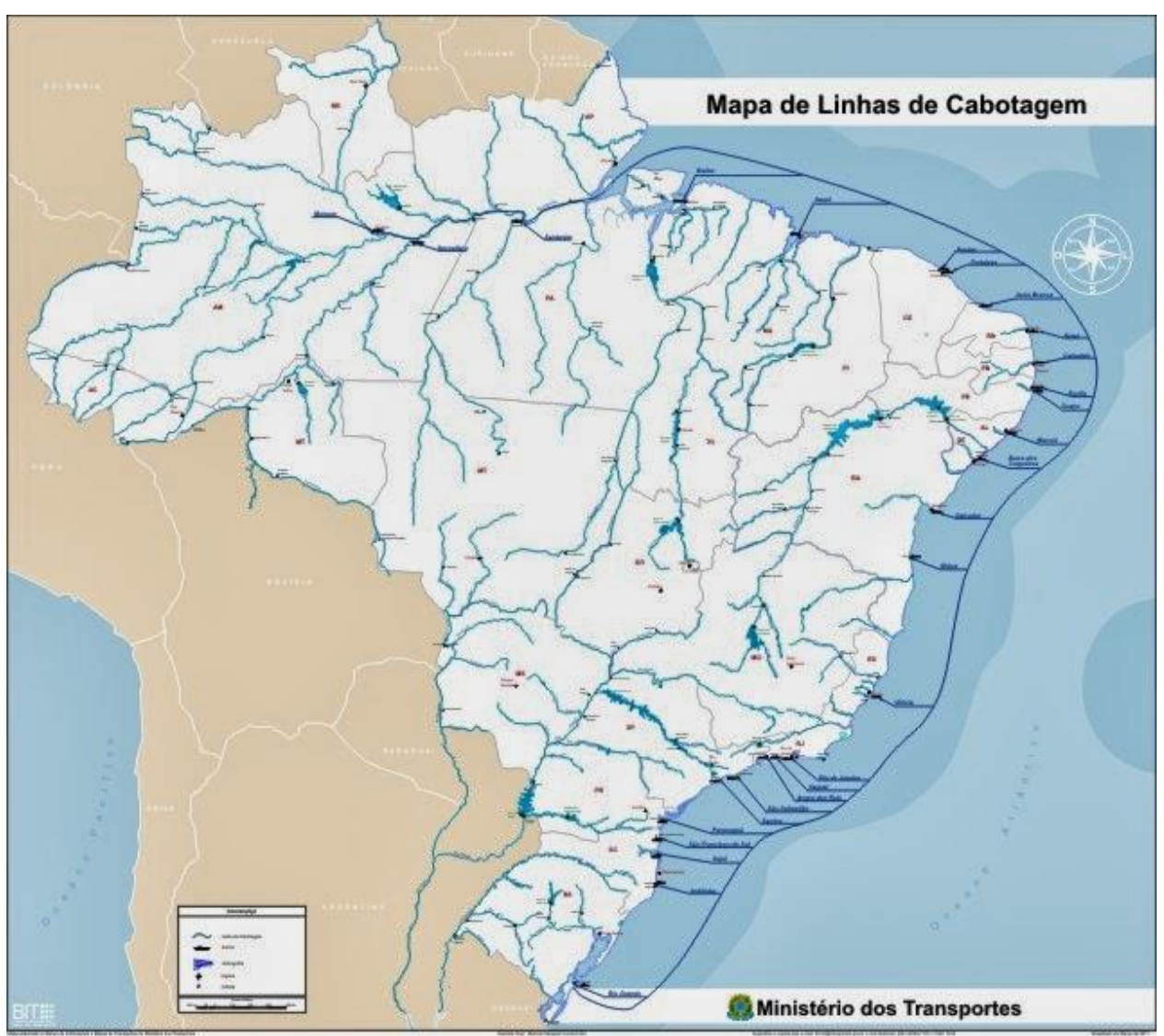

Fonte: Ministério dos Transportes (2013)

No contexto atual, necessita-se de uma reestruturação do modelo de transportes nacional, em especial dos portos brasileiros para navegação marítima, com vistas, principalmente, ao atendimento de passageiros. Segundo 
dados da ANTAQ - Agência Nacional de Transportes Aquaviários (2011) -, estão destinados de $\mathrm{R} \$ \mathbf{7 4 0}$ milhões até um bilhão de reais para a reestruturação dos portos localizados nas cidades-sede dos jogos da Copa do Mundo de Futebol (2014), o que já se apresenta como uma notícia promissora em vista da situação atual de precariedade. Mas se torna necessário ampliar essa rede de investimentos para gerar novos destinos turísticos reais para os navios de cruzeiros marítimos no País, principalmente para atender às necessidades de consumo advindas de novos navios, especialmente os de passageiros, pois as embarcações contemporâneas apresentam um diferencial técnico em relação à capacidade de transporte e equipamentos de lazer, quer dizer, a capacidade das novas embarcações permite supor que ocorre um fenômeno de grandes volumes de passageiros com caráter impactante nas localidades, visto que é possível ter a população de uma cidade, como Macuco (IBGE, 2013), cerca de cinco mil pessoas, dentro de um navio. Vale lembrar que esse é o número total de passageiros do Carnival Triumph. Além disso, não se pode esquecer que os equipamentos de lazer existentes nas modernas embarcações não são encontrados, muitas vezes, em resorts no Brasil, apenas em parques temáticos como Epcot Center, nos Estados Unidos.

Outro fator preponderante que corrobora o investimento nacional no segmento de cruzeiros marítimos refere-se ao fluxo de turistas oriundos dos cruzeiros marítimos, principalmente nas cidades do eixo litorâneo onde os navios aportam, pois impulsionam a economia local por meio da utilização de equipamentos turísticos, deixando em troca somas vultosas em dinheiro como ocorreu no Rio de Janeiro, no ano de 2011, onde circularam, segundo a RIOTUR (2011), cerca de 210 milhões de dólares somente pelo fluxo de passageiros dos cruzeiros marítimos, que movimentaram, segundo a mesma pesquisa, uma média de gastos de US\$200,10 dólares por passageiro/dia. 
Entretanto, em virtude das embarcações, ocorrem problemas imediatos nas localidades portuárias brasileiras, em especial, os estruturais que causam sérios problemas - como o leito raso dos canais que pode gerar o atolamento dos navios, a ausência de terminal para embarque e desembarque adequado aos passageiros - e inibem a franca expansão desse segmento em território nacional. Espera-se que as ações previstas pela ANTAQ possam resolver definitivamente tais problemas para a expansão não somente do segmento de cruzeiros marítimos, mas também da navegação marítima no Brasil.

\section{Tipologia das Embarcações}

Quanto a este item, é importante conhecer a obra de Ward (1999, p.153332 passim), na qual se abordam as formas de reconhecimento das embarcações por período de construção, tamanho e equipamentos disponíveis aos passageiros. Ao analisá-la, o profissional de turismo poderá identificar o produto mais indicado a cada tipo de passageiro.

As embarcações para cruzeiros marítimos dividem-se, pois, em três tipos, conforme Fujita (2005): embarcações clássicas - anteriores e posteriores à Segunda Guerra - , modernas e contemporâneas.

Figura 2. Navio MS Funchal - Ano de construção 1961

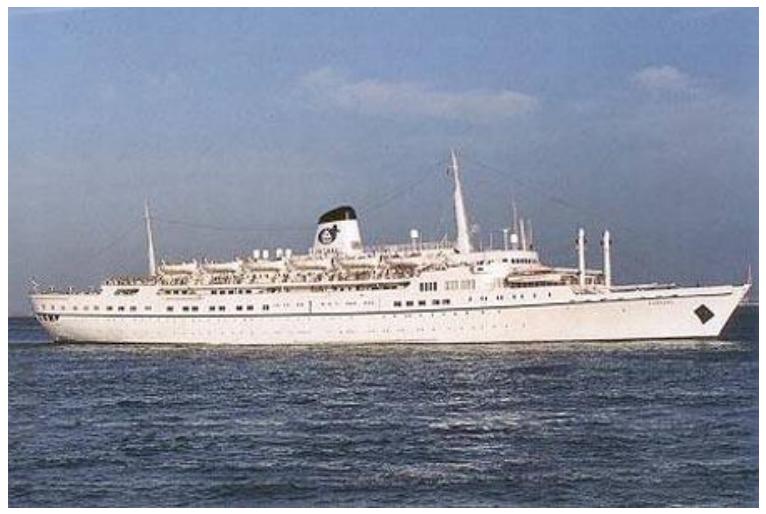

Fonte: Arcalia Shipping Cruise (2009) 
Os navios referentes aos períodos de guerra e pós-guerra (vide Figura 2), têm o desenho tradicional, isto é, os extremos da embarcação formam um desenho quase simétrico em ângulo e formato, e a parte posterior não é tão pontiaguda. Além disso, dispõem de áreas planas, onde se localizam, geralmente, piscinas e jacuzzis ${ }^{12}$. A configuração das cabines, quanto às categorias, não segue uma padronização (Figura 3), pois são construídas de formas e tamanhos diferenciados, atendendo a uma adaptação à estrutura de um navio já consolidado ${ }^{13}$. As áreas de lazer ${ }^{14}$ encontram-se prejudicadas, tanto em localização, quanto em relação ao tamanho, visto serem também adaptadas a um espaço já construído. Entretanto, em alguns navios, criaram-se novas áreas na estrutura já concebida, como os elevadores panorâmicos do SS Norway, construídos nas laterais externas do navio, pois não havia como incluílos na estrutura interna da embarcação, e o hall de entrada de cristal do TSMV Queen Elizabeth 2, adaptado à estrutura do navio para que os passageiros entrem pela parte superior da embarcação, e não pelos decks inferiores, em virtude da construção de fingers (pontes) nos portos norte-americanos e europeus que ligam o terminal de passageiros diretamente aos navios.

As embarcações são geralmente de pequeno e/ou médio porte quanto à capacidade de passageiros, girando em torno de 250 a mil viajantes (SCHULTZ; SPRINGER, 1999, p. 36).

\footnotetext{
12 Banheiras de hidromassagem com capacidade de quatro a 16 pessoas, localizadas nas áreas externas do navio e de uso coletivo.

${ }^{13}$ As categorias de cabine são distribuídas por conjunto de cores, tendo-se a variação na metragem da cabine numa mesma faixa de preço, o que pode gerar certo descontentamento por parte do passageiro que pode se sentir lesado caso compre uma cabine menor do que outro passageiro na mesma categoria de preço.

${ }^{14}$ Os equipamentos de lazer, como piscina, salas de shows, danceterias e salões de refeição, são adaptados à estrutura, deixando-os com tamanhos e configurações desproporcionais à quantidade de passageiros e ao perfil de consumo.
} 
Figura 3. Deck plan15 do navio Funchal - as cabines não padronizadas na mesma categoria de preço

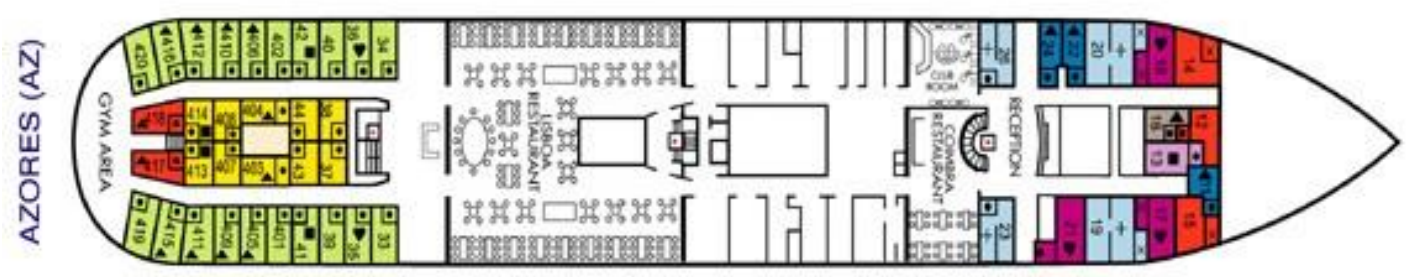

Fonte: Arcalia Shipping Cruise (2009).

Figura 4. Island Escape - ano de construção 1982

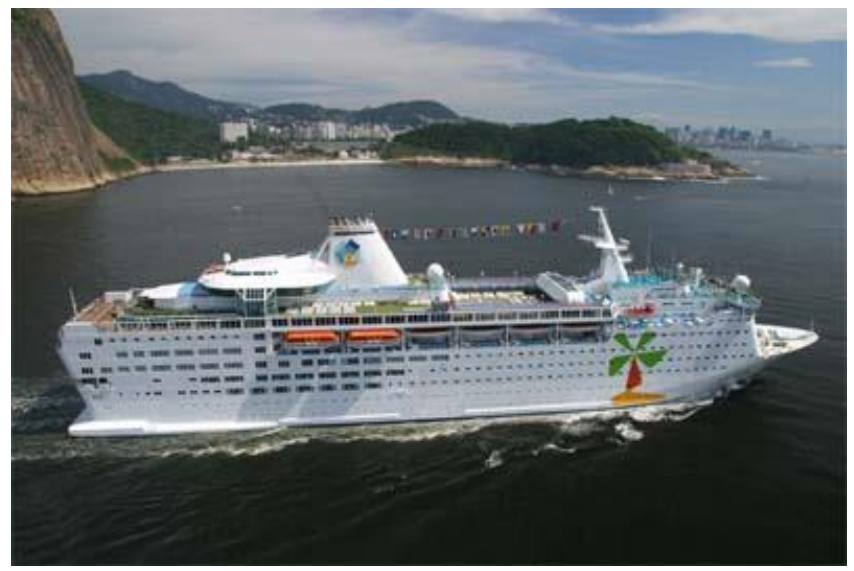

Fonte: Island Cruises (2009).

Os navios do período moderno (vide Figura 4), construídos a partir de 1970 (DICKINSON; VLADIMIR, 1997, p. 37-63), apresentam-se com o formato clássico, sem a ocupação direta, tanto da proa (parte frontal do navio), quanto da popa (parte posterior da embarcação), por cabines, utilizadas como áreas de lazer. Têm a configuração interna padronizada (Figura 5) com a divisão correta das cabines e a localização central das áreas de lazer no navio. A adoção de equipamentos de segurança e navegação por satélite já consta do projeto

\footnotetext{
${ }^{15}$ Deck plan - Mapa ilustrativo dos andares de um navio, geralmente fixado nas áreas de acesso da embarcação, como elevadores e atrações principais. Tem como intuito facilitar a localização do passageiro para que possa se movimentar a bordo.
} 
original. Essas embarcações são construídas prevendo-se os espaços de lazer e com capacidade mínima para 1.100 passageiros, como se dá nos navios MS Celebration e MS Crown Odyssey.

Figura 5. Deck plan do navio Island Scape - cabines padronizadas na mesma categoria de preço

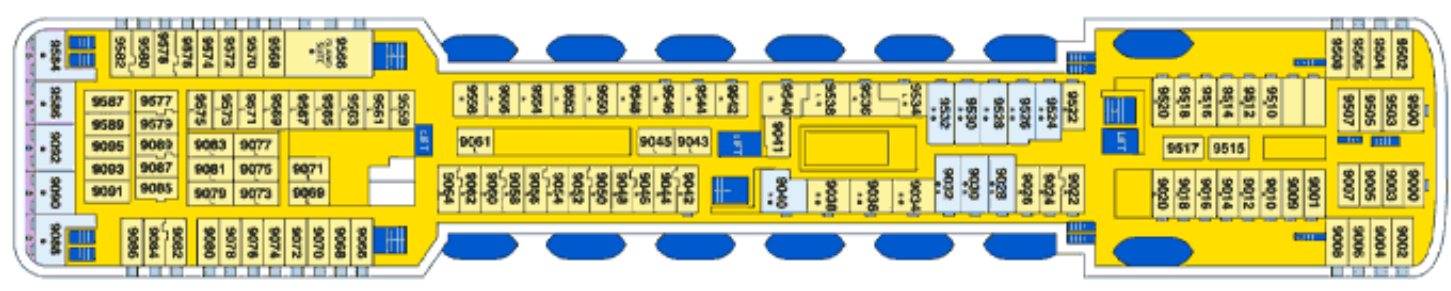

Fonte: Island Cruises (2009).

Figura 6. Costa Victoria - ano de construção 1996

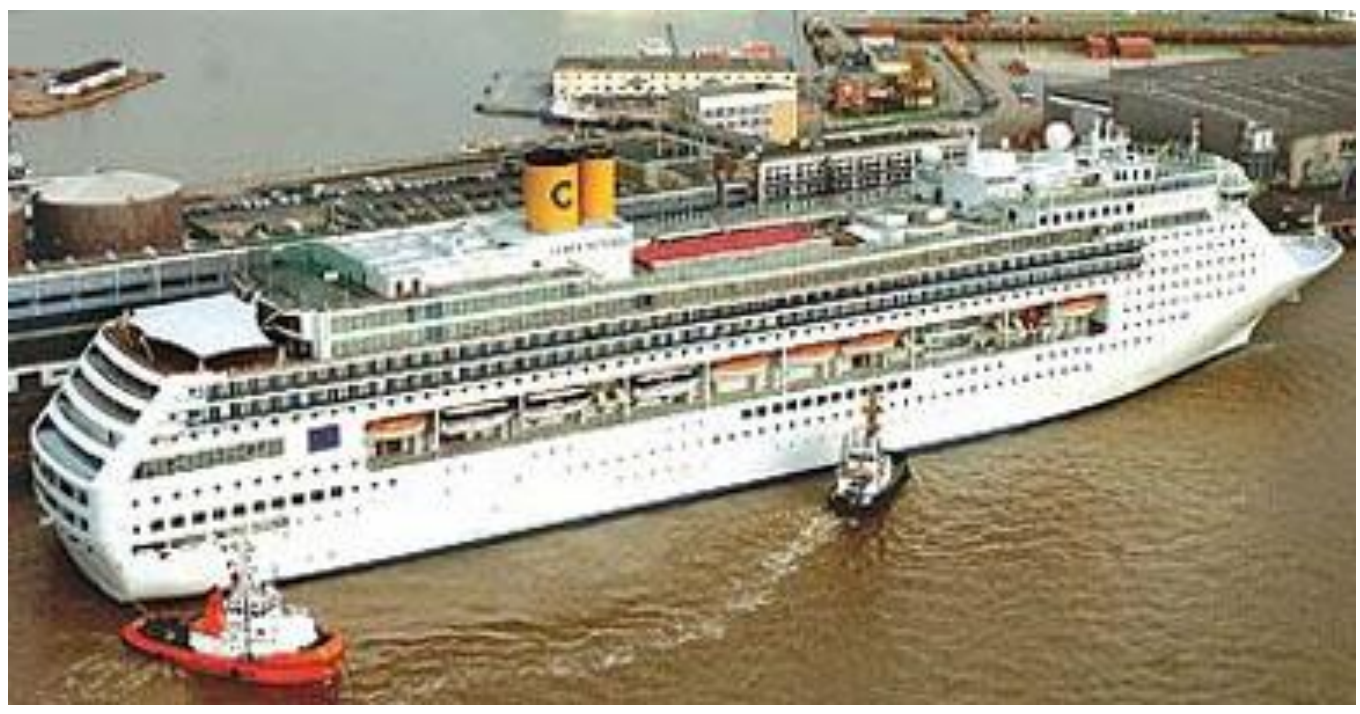

Fonte: Costa Cruzeiros (2013). 
As embarcações contemporâneas (vide Figura 6), construídas a partir de 1990 (FUJITA, 2005), têm um formato diferenciado, pois a proa e a popa já não apresentam o mesmo alinhamento e a mesma configuração, isto é, tanto a parte dianteira, quanto a parte traseira são construídas de forma quase reta, para que possam incluir cabines com varandas panorâmicas - uma exigência mercadológica. Os equipamentos de lazer são os mais diferenciados possíveis, desde salas de realidade virtual até rinques no gelo, incluindo-se o conceito de bairros, que, na verdade, são decks temáticos que replicam o cenário de cidades ou até de países. São produtos completos em matéria de hospitalidade e diversão. Nota-se também que há mais cabines com varandas, podendo chegar ao extremo de $70 \%$ do total de cabines na embarcação com algum tipo de vista (as varandas podem ser voltadas para o interior do navio). As áreas de lazer ocupam quase toda a extensão da embarcação (Figura 7), e os restaurantes principais são disponibilizados na parte central do navio. Essas embarcações costumam ter uma capacidade mínima de 3.500 passageiros, como nos navios Carnival Destiny e Voyager of the Seas, tendo-se até 5.400 passageiros na maior embarcação disponível no momento (Allure of the Seas - Armadora Royal Caribbean).

Figura 7. Deck plan do navio Costa Romantica - deck destinado ao lazer (seguindo-se a sequência de pontos vermelhos a partir da proa, tem-se o Teatro l'Opera, as lojas, o cassino Excelsior e a pista de dança do salão Tango, respectivamente)

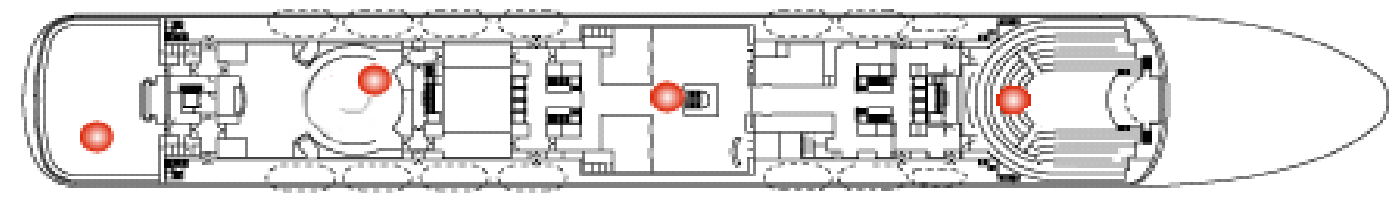


Pode-se constatar que ocorre uma evolução constante das embarcações no intuito de agregar mais equipamentos e opções de lazer, incluindo-se, na questão da hospitalidade, cabines cada vez maiores e mais confortáveis, além de opções de alimentação, com diversos tipos de restaurantes - que funcionam 24 horas ininterruptas - e, principalmente, novos sistemas de segurança, como o Sistema de Posicionamento Global - GPS -, sincronizados em tempo real, e câmeras de monitoramento de percurso.

Além das questões de infraestrutura, nos cruzeiros marítimos no Brasil, adotam-se estratégias de hospitalidade comercial para atender às necessidades específicas do público brasileiro, como a oferta do sistema All Inclusive (Tudo Incluso) em detrimento do convencional Almost All Inclusive (com bebidas cobradas à parte e somente inclusas as refeições), o parcelamento das excursões em terra e sua compra antecipada, o turno livre de refeição (não havendo a necessidade de marcação de assentos para o jantar), o cumprimento da normativa de tripulação brasileira ${ }^{16}$ e a oferta de cruzeiros temáticos.

As tendências socioeconômicas estão influenciando a demanda por cruzeiros. A classe média emergente em países, como a Coreia e o Brasil, produz novos mercados de potenciais clientes, ricos e com boa formação educacional. (COULSON apud LOCKWOOD; MEDLIK, 2003, p. 230).

Ao compreender a afirmação anterior, percebe-se que os turistas brasileiros almejam um padrão mais elevado de serviços turísticos e de hospitalidade, que começam a desenvolver-se no cenário nacional, e que os cruzeiros marítimos, representantes dessa necessidade, trazem qualidades aparentemente superiores a alguns equipamentos turísticos tradicionais, como hotéis e restaurantes.

\footnotetext{
16 Na Resolução Normativa - RN - n.o 71, editada e publicada pelo Conselho Nacional de Imigração (CNIg) em 2006, está expresso que as embarcações estrangeiras de turismo devem ser compostas por $25 \%$ de brasileiros (no mínimo) na tripulação, a partir do 31.o dia de operação na costa brasileira.
} 
A hospitalidade comercial é um dos atrativos que distinguem os cruzeiros marítimos dos demais equipamentos turísticos no Brasil, tendo-se, mesmo assim, o cuidado na oferta desse serviço para que a infraestrutura da embarcação seja adequada (categoria) à necessidade e ao perfil do consumidor final.

O consumidor do futuro não só aprofundará seus conhecimentos pessoais e suas competências, como também se tornará mais e mais exigente. A transparência do mercado aumentará e os consumidores esperarão receber detalhes e informações relevantes sem ter que se preocupar em coletar esses dados. Aqueles dias em que as seleções e as tomadas de decisões eram feitas apenas com base nos preços - exceto pelas ofertas que são realmente verdadeiras barganhas - não existem mais (AFFOLTER apud LOCKWOOD; MEDLIK, 2003, p. 254).

Portanto o estudo e a compreensão das categorias dos cruzeiros marítimos tornam-se fundamentais para que se atendam as expectativas do consumidor, uma vez que, somente pelo benefício dos serviços (relação custo $X$ benefício - transporte, hospedagem e serviços), a semelhança entre os roteiros executados pelas armadoras e as promoções empreendidas não se concretizam efetivamente em diferenciais competitivos no segmento, embora sejam realmente a característica de distinção na categoria das embarcações.

\section{Considerações Finais}

Num país que apresenta um extenso litoral, como o Brasil, é preciso identificar no mar as grandes potencialidades que podem gerar novas fontes de recursos, o que possibilitaria o nascimento de uma nova política marítima mais eficaz e eficiente para aproveitamento de tais riquezas.

No caso brasileiro, os interesses marítimos são históricos e amplos, e o mar é o principal responsável pelo descobrimento e é, também, fonte da 
colonização. E mais: tem papel importante nos momentos de invasão, consolidação da independência, comércio e agressões, além de arena de defesa da soberania em diversos episódios, até mesmo em duas guerras mundiais no século passado.

A importância do mar ainda se relaciona com o desenvolvimento e a soberania do País e é o ponto principal de escoamento da produção que gera as principais divisas brasileiras.

Assim, é importante desenvolver o conceito de hospitalidade nos principais portos de passageiros para que ali se reflitam as condições básicas e de atratividade e se tornem sustentáveis e financeiramente viáveis, além da expansão para outras localidades do eixo litorâneo como alternativa para a captação de recursos e variabilidade dos roteiros.

Por isso, os cruzeiros podem ser a fonte primária de entrada de capitais para diversas localidades, principalmente quando do desembarque do turista, que se utiliza dos serviços locais, movimentando a economia das cidades portuárias e gerando novos empregos e fontes de renda, como percebido pelos números apresentados pela RIOTUR.

Não obstante, no contexto atual, a categoria dos cruzeiros marítimos transforma-se no principal mote de distinção entre as empresas fornecedoras do serviço, em virtude da precariedade dos roteiros e da semelhança dos benefícios ofertados, mesmo apresentando qualidade relativamente superior aos demais equipamentos de turismo no Brasil.

A evolução e a expansão do segmento, que se encontram saturadas no momento, dependem de investimentos para que embarcações cada vez maiores e melhores possam aportar em território nacional e ocorra uma ampliação na oferta de roteiros que possibilitarão a retomada de crescimento do segmento e o aumento do fluxo de passageiros, atendendo e criando até 
novas necessidades e desejos no turista nacional em relação aos cruzeiros marítimos.

Constata-se, pois, que os cruzeiros marítimos provocam grande expectativa no País; por isso, é necessário planejar adequadamente a concretização deles, pois, enquanto perdurarem situações constrangedoras nos portos e negligência no investimento em políticas eficazes para o fomento desse processo, não haverá possibilidade de rentabilidade total, e será um desperdício em relação a esse excelente equipamento. Para solucionar tal situação, é preciso que haja união entre o Poder Público e os profissionais do segmento, para que, juntos, alcancem todo o potencial de hospitalidade representado pelos cruzeiros marítimos no Brasil.

Novamente, o mar propicia mais uma dádiva ao Brasil na figura de cruzeiros marítimos, equipamentos turísticos e hospitalidade completa, que realça um dos principais dons nacionais: a hospitalidade incondicional. Porém, para que esse desenvolvimento ocorra, é importante fomentar rapidamente novos estudos e pesquisas sobre o assunto, pois a compreensão sobre 0 segmento é o primeiro passo para empreender novos caminhos e elaborar novas diretrizes de ação que permitirão também o possível desenvolvimento econômico das localidades portuárias, mas, principalmente, a afirmação do País como um destino turístico e de hospitalidade sólido, tanto no âmbito nacional, quanto no internacional.

\section{Referências}

ABREMAR - Associação Brasileira de Cruzeiros Marítimos (São

Paulo). Temporadas. Disponível em: <http://www.abremar.com.br/temporadas/>. Acesso em: 15 nov. 2013. 
AFFOLTER, D. O mercado do turismo: novos desafios. In: LOCWOOD, A.; MEDLIK, S. Turismo e hospitalidade no século XXI. São Paulo: Manole, 2003, p. 251256.

BRASIL. Congresso. Senado. Decreto n.o 123, de 11 de janeiro de 1892. Regula a navegação de cabotagem. Rio de Janeiro, RJ, 11 jan. 1892. Disponível em: $<$ http://legis.senado.gov.br/legislacao/ListaTextolntegral.action?id=48984\& norma $=64765>$. Acesso em: 15 dez. 2013.

. IBGE - Instituto Brasileiro de Geografia e Estatísticas. Cidades.

Disponível

em:

$<$ http://cidades.ibge.gov.br/xtras/perfil.php?lang=\&codmun=330245\& search=riode-janeiro |macuco>. Acesso em: 18 nov. 2013.

Lei n. 9.432, de 8 de janeiro de 1997. Dispõe sobre a ordenação do transporte aquaviário e dá outras providências. Brasília, DF, 9 jan. 1997. Disponível em: <http://www.planalto.gov.br/ccivil_03/leis/l9432.htm>. Acesso em: 15 dez. 2013.

SNM - Superintendência da Navegação Marítima e de Apoio. Agência Nacional de Transportes Aquaviários. Panorama da navegação marítima e de apoio. Disponível em: <http://www.antaq.gov.br/portal/pdf/BoletimPortuario/PanoramaNavega caoMaritima Apoio2011.pdf>. Acesso em: 18 nov. 2013.

CAMARGO, L. O. L. Hospitalidade. São Paulo: Aleph, 2004.

COLLINDER, P. A history of marine navigation. Londres: B. T. Batsford, 1954.

COULSON, B. O futuro dos cruzeiros marítimos. In: LOCKWOOD, A.; MEDLIK, S. Turismo e hospitalidade no século XXI. São Paulo: Manole, 2003, p. 227-232. DEYON, P. O mercantilismo. São Paulo: Perspectiva, 1973.

DICKINSON, R.; VLADIMIR, A. N. Selling the sea: an inside look at the cruise industry. New York: John Wiley \& Sons, 1997.

FUJITA, D. M. Hospitalidade nos cruzeiros marítimos no litoral brasileiro: estudo de caso da Companhia Costa Cruzeiros. 2005. 113 f. Dissertação (Mestrado) Curso de Mestrado em Hospitalidade, Departamento de Turismo e Hospitalidade, Universidade Anhembi-Morumbi, São Paulo, 2005. Disponível em: <http://www.dominiopublico.gov.br/ download/texto/cp001486.pdf>. Acesso em: 27 jun. 2013.

INGLATERRA. IMO - International Maritime Organization. United Nations World Health Organization. International convention for the safety of life at sea (SOLAS), $1974 . \quad$ Disponível em: <http://www.imo.org/about/conventions/listof conventions/pages/ international-convention-for-the-safety-of-life-at-sea-(solas),-1974.aspx >. Acesso em: 27 jun. 2013.

MORIN, E. Cultura de massas no século XX: o espírito do tempo. São Paulo: Forense, 1967. . Les Stars. Paris: Seuil, 1972. 
MOUSNIER, R. História geral das civilizações: os séculos XVI e XVII. Livro 1. São Paulo: Difel,1973.

PRADO, L. Transporte e corrupção: um desafio à cidadania. Rio de Janeiro: Topbooks, 1997.

RONÁ, R. Transportes no turismo. São Paulo: Manole, 2002.

RIO DE JANEIRO. RIOTUR - Empresa de Turismo do Município do Rio de Janeiro. Secretaria Especial de Turismo do Rio de Janeiro. Temporada de transatlânticos irá gerar US\$ 210 milhões para o Rio. 2011. Disponível em: <http://www.rio.rj.gov.br/web/riotur/exibeconteudo?id=2256158>. Acesso em: 13 ago. 2013.

SCHULTZ, D.; SPRINGER, M. Frommer's comprehensive travel guide: cruises '98'99. New York: Prentice Hall, 1999.

TELFER, E. A filosofia da qualidade da hospitalidade. In: LASHLEY, C.; MORRISON, A. Em busca da hospitalidade: perspectivas para um mundo globalizado. São Paulo: Manole, 2004.

TOMA, M. A pena de degredo e a construção do império colonial. Curitiba: UFPR, 2011. Disponível em: < http://www.humanas.ufpr.br/portal/cedope/files/2011/12/A-pena-de-degredo-ea-constru\%C3\%A7\%C3\%A3o-do-imp\%C3\%A9rio-colonial-Maristela-Toma.pdf>. Acesso em: 13 ago. 2013.

TORRE, F. Sistemas de transporte turístico. São Paulo: Roca, 2002.

WARD, D. Berlitz: complete guide to cruising and cruise ships. New York: Berlitz, 2003. 


\section{Dennis Minoru Fujita}

Professor Convidado do Curso de Especialização em Gastronomia - Universidade de Guarulhos Professor Convidado do Curso Superior de Tecnologia em Gastronomia - Univille Bolsista CAPES

Doutorando do Programa de Pós-Graduação em Medicina Tropical da USP

Mestre em Hospitalidade pela Universidade Anhembi Morumbi (2005)

Bacharel em Turismo pelo Centro Universitário Ibero-Americano (2001)

dmfujita@usp.br

Av. Dr. Enéas de Carvalho Aguiar, 470 - Prédio I

Cep: 05403-000 - Cerqueira César - São Paulo - SP

\section{Heitor Franco de Andrade Júnior}

Professor Associado da Faculdade de Medicina e do Instituto de Medicina Tropical de São Paulo da USP

Chefe do Laboratório de Protozoologia do Instituto de Medicina Tropical de São Paulo da USP Responsável pelas disciplinas de graduação em saúde em viagens para a graduação em Turismo da ECA-USP

Pesquisador em Doenças Tropicais e saúde internacional Livre-docente em Patologia de Moléstias Transmissíveis

Doutorado em Patologia

Especialização em Residência Médica Em Clínica Médica e Reumatologia

Graduado em Medicina

hfandrad@usp.br

Av. Dr. Enéas de Carvalho Aguiar, 470 - Prédio I

Cep: 05403-000 - Cerqueira César - São Paulo - SP

Agradecimento/Financiamento CAPES e LIM - 49/HCFMUSP 